\title{
RESEARCH
}

Open Access

\section{Impact of 2017 ACC/AHA guideline on prevalence, awareness, treatment, control, and determinants of hypertension: $a$ population-based cross-sectional study in southwest of Iran}

Fatemeh Sadeghi', Bahman Cheraghian², Zahra Mohammadi ${ }^{3}$, Sadaf G. Sepanlou ${ }^{4}$, Sahar Masoudi ${ }^{3}$, Zahra Rahimi ${ }^{5}$, Leila Danehchin ${ }^{6}$, Yousef Paridar ${ }^{7}$, Farhad Abolnezhadian ${ }^{8,9}$, Mohammad Noori ${ }^{10}$, Seyed Ali Mard ${ }^{11}$,

Ali Akbar Shayesteh ${ }^{11^{*}}$ and Hossein Poustchi ${ }^{3^{*}}$ (D)

\begin{abstract}
Background: In 2017, the American College of Cardiology/American Heart Association (ACC/AHA) provided a new guideline for hypertension prevention and management. We aimed to update the prevalence, awareness, control, and determinants of hypertension based on this guideline in Khuzestan province, southwest of Iran, and to estimate the number of people who are eligible for non-pharmacologic and pharmacologic intervention.

Methods: This population-based cross-sectional study was conducted in Khuzestan, a large province in the southwest of Iran. Comprehensive information about the potential relating factors of hypertension was collected, blood pressure was measured, and anthropometric measurements were obtained. Moreover, the dietary pattern was evaluated in 2830 individuals, using a qualitative food frequency questionnaire.
\end{abstract}

Results: Among 30,506 participants, 30,424 individuals aged 20-65 years were eligible for the study. In comparison with the previous guideline released by the Joint National Committee (JNC8), the prevalence of hypertension in Khuzestan dramatically increased from 15.81 to $42.85 \%$ after implementation of the ACC/AHA guideline, which was more dominant in the male population and the 45-54 age group. The sex and age adjustment of the hypertension prevalence was estimated to be $39.40 \%$. The percentage of hypertension awareness, treatment, and control were $45.85 \%, 35.42 \%$, and $59.63 \%$, which dropped to $22.72 \%, 26.37 \%$, and $28.94 \%$ after implementation of new guideline, respectively.

\footnotetext{
*Correspondence: shayeste-a@ajums.ac.ir; h.poustchi@gmail.com

${ }^{11}$ Alimentary Tract Research Center, Imam khomeini Hospital Clinical Research Development Unit, School of Medicine, Ahvaz Jundishapur University of Medical Sciences, Ahvaz, Iran

${ }^{3}$ Liver and Pancreatobiliary Diseases Research Center, Digestive Diseases Research Institute, Tehran University of Medical Sciences, Tehran, Iran Full list of author information is available at the end of the article
}

(c) The Author(s). 2021, corrected publication 2021. Open Access This article is licensed under a Creative Commons Attribution 4.0 International License, which permits use, sharing, adaptation, distribution and reproduction in any medium or format, as long as you give appropriate credit to the original author(s) and the source, provide a link to the Creative Commons licence, and indicate if changes were made. The images or other third party material in this article are included in the article's Creative Commons licence, unless indicated otherwise in a credit line to the material. If material is not included in the article's Creative Commons licence and your intended use is not permitted by statutory regulation or exceeds the permitted use, you will need to obtain permission directly from the copyright holder. To view a copy of this licence, visit http://creativecommons.org/ licenses/by/4.0/. The Creative Commons Public Domain Dedication waiver (http://creativecommons.org/publicdomain/zero/1. 0/) applies to the data made available in this article, unless otherwise stated in a credit line to the data. 
Conclusions: In the ACC/AHA guideline, a higher number of individuals with the pre-hypertension condition were shifted into the hypertension category and the level of awareness, treatment, and control were dramatically decreased, which highlight a great need to expand the public health infrastructure for further managing the substantial increased burden on healthcare system. However, further studies with population over 65 years are required to estimate the eligibility for antihypertensive treatment in this province after implementation of new guideline.

Keywords: Hypertension, Iran, 2017 ACC/AHA hypertension guideline, JNC8 hypertension guideline, Risk factors, Prevalence, Awareness, Treatment, Control

\section{Background}

Hypertension (HTN) is a major risk factor for noncommunicable diseases such as cardiovascular diseases (CVD), stroke, and renal dysfunction. With 1.5 billion hypertensive people and 7.6 million HTN-related death, this disease remains major public health globally $[1,2]$. In low- and middle-income countries (LMICs), such as Iran, the prevalence of HTN is increasing rapidly and it is estimated about three-fourths of the world's hypertensive population will be from these countries by 2025 [2]. In Khuzestan province, a large proportion of the population is living with HTN [3]. Considering the high prevalence of HTN and its cost comorbidities, mainly on low resource settings with weak health systems, being updated about the indicators of HTN is essential to improve the approaches to control this disorder, and measuring progress towards the goals of Universal Health Coverage (UHC) of HTN.

The 6th 5-year National Plan of Economic, Social and Cultural Development of Islamic Republic of Iran (2017-2021) prioritizes the health of the population by expanding health service coverage and increasing financial protection mechanisms [4]. Achieving and sustaining UHC of HTN requires assessing the longer-term costs of health care, which is highly dependent on the HTN indicators such as prevalence, awareness, treatment, and control. According to the eighth report of the joint national committee (JNC8) guideline, patients with systolic blood pressure (SBP) $\geq 140 \mathrm{mmHg}$ and/or diastolic blood pressure (DBP) $\geq 90 \mathrm{mmHg}$ were diagnosed with HTN [5]. Using this report, the overall prevalence, awareness, treatment and control of HTN in Iran were estimated to be $29.9 \%, 59.2 \%, 80.2 \%$, and $39.1 \%$, respectively [6]. However, recently the 2017 American College of Cardiology (ACC)/American Heart Association (AHA) recommended SBP/DBP $\geq 130 / 80 \mathrm{mmHg}$ as a new cut-off for HTN, indicating the HTN estimations are required to be updated in all regions for development of more cost-effective UHC interventions in the management of HTN [7]. To date, few studies have evaluated the impact of suggested guideline and have reported that shifting from JNC8 to 2017 ACC/AHA causes a significant increase in the prevalence of HTN and a drastic decline in awareness, treatment, and control of this disorder $[6,8,9]$. This impact is more dominated in LMICs like 15-49-year-old Indian people (from 13.0 to 40.6\%) [9], which may impose a considerable impact on health systems due to the challenges in terms of coverage and access to health service.

HTN is a multifactorial disease, and several genetic, environmental, and behavioral factors contribute to its manifestation [10]. Low physical activity and overweight, as well as unhealthy diet such as high salt intake, are the leading risk factors of HTN [11]; nevertheless, considerable variations between countries and even within the countries exist. Although this disease is usually asymptomatic and people are not aware of their condition, it is one of the most preventable disorders and modifications of the lifestyle could considerably prevent the future progression of HTN into CVD and renal diseases. In the ACC/AHA guideline, a higher number of individuals with the pre-hypertension condition are shifted into the HTN category [7]. Being updated about the major determinants of HTN is a prerequisite for effective prevention and promotion of awareness strategies in the future.

Khuzestan is located in the of the southwest of Iran. This province with 4,936,000 population has been exposed to different life-threatening issues such as dust storms, extremely high temperatures, air pollution, and soil contamination [12]. According to JNC8 report, the prevalence of hypertension in Ahvaz, the capital city of this province, was estimated to be $17.58 \%$, with $46.4 \%$ awareness and 22\% control rate [3]. Among thirty-one provinces of Iran, this province had the lowest level of healthcare development and highest inequality of health services utilization in the country [13]. Therefore, the implementation of the 2017 ACC/AHA guideline may considerably delay the progression towards UHC of HTN in this province. Here, we aimed to update the estimates in a large sample of participants in Khuzestan Comprehensive Health Study to aid public health resources planning and prevention strategies.

\section{Methods}

Study design and study population

This cross-sectional health survey was conducted based on the data of Khuzestan Comprehensive Health Study (KCHS). KCHS is a large population-based cross-section 
study with the purpose of evaluating the health status of the Iranian adults in Khuzestan. This study was performed in the period of October 2016 to November 2018 and the participants were selected using a multistage random sampling method. In the first stage of cluster sampling, the health centers and health houses within each county were selected randomly (total 29 counties). According to the population of each county, a total number of 1079 of clusters, consisting of 780 health centers in urban and 299 health houses in rural areas, were chosen. Afterward, 30 individuals between 20 and 66 years old were selected within each cluster, using systematic random sampling.

The individuals who had been selected in the sampling process and were residents of Khuzestan province for at least 1 year were invited to participate in the study by a trained staff. We excluded individuals with mental, psychological or physical disabilities, or if they were reluctant to participate at any stage of the study. A written informed consent was obtained from all contributors before including them in the study. The sampling frame and study design has been described previously [14].

\section{Blood pressure and anthropometric measurements}

The SBP and DBP were measured twice with 10-min interval in a seated position using analogue Riester sphygmomanometers. In addition, the participants' height and weight were measured by Seca 206 body meter measuring tape and Seca 762 mechanical flat scale, respectively.

\section{Laboratory measurements}

After overnight fasting, 15-ml peripheral blood was collected from each participant and was transferred to a research lab in a $4^{\circ} \mathrm{C}$ cold boxes within $3 \mathrm{~h}$. After separating the serum, the levels of fasting blood sugar (FBS), total cholesterol, high-density lipoproteins (HDL) cholesterol, and low-density lipoprotein (LDL) cholesterol were measured.

\section{Dietary intake assessment}

The dietary habits were assessed for 2830 randomly selected participants, and the consumption of sodium, total fat, fiber, and carbohydrate was measured per week. Briefly, an 86-item qualitative food frequency questionnaire (FFQ) was designed based on previous studies on major sources of the nutrients of interest in the Iranian diet. To estimate average food consumption frequency in the last year, we used closed-ended responses consisting of 9 categories: never or less than once/month, 1-3/ month, 1-2/week, 3-4/week, 5-6/week, 1/day, 2-3/day, or $>4 /$ day. The standard portion size was estimated and the micronutrient and macronutrient information were obtained from the United States Department of Agriculture (USDA) database [15].

\section{Outcome definitions}

According to the 2017 ACC/AHA guideline, HTN was defined if the SBP level was $\geq 130 \mathrm{mmHg}$ and/or the DBP level was $\geq 80 \mathrm{mmHg}$ and/or the participant takes antihypertensive medication [7]. These thresholds were $\mathrm{SBP} \geq 140$ and/or $\mathrm{DBP} \geq 90$ based on the JNC8 report [5].

Awareness was estimated among HTN-identified individuals if they responded positive to the self-reported of physician-diagnosed HTN. Treatment was defined as positive if self-aware individuals answered yes to the questions "Are you currently taking antihypertensive drug?" Moreover, the HTN control was defined among treated individuals with blood pressure $<130 / 80 \mathrm{mmHg}$ based on the 2017 ACC/AHA or $<90 / 140 \mathrm{mmHg}$ based on the JNC8 after taking anti-HTN drugs.

\section{Covariates definitions}

Covariates included demographic, economic status, lifestyle, and CVD risk factors. Age groups included $<25$, 25-34, 35-44, 45-54, 55-64, or 65 years. Marital status consisted of single, married, divorced, or widow. Education was categorized according to the educational system in Iran as either illiterate ( $<1$-year study), elementary school (1-5-year study), guidance school (6-8-year study), high school (9-12-year study), or universities (>12-year study) [16], and ethnicity classification was done based on major ethnic groups located in this province (Fars, Arab, Bakhtiary, Lor) [12]. The economic status was defined according to the wealth index, which was calculated by multiple correspondence analysis (MCA) with household's ownership of selected assets and was further presented in quartiles [17].

Body mass index (BMI) was calculated by dividing weight (in kilograms) to height (in meters, squared) and further classified based on the WHO international BMI classification, as either underweight (< $\left.18.5 \mathrm{~kg} / \mathrm{m}^{2}\right)$, normal $\left(18.5-24.9 \mathrm{~kg} / \mathrm{m}^{2}\right)$, overweight $\left(25.0-29.9 \mathrm{~kg} / \mathrm{m}^{2}\right)$, or obesity $(\geq 30)[18]$. Waist-to-hip ratio (WHR) was the ratio of waist circumference to hip circumference. Physical activity was estimated by metabolic equivalent of task (MET) category, which was calculated based on the international physical activity questionnaire (IPAQ) guideline and classified as either insufficient (MET<600/week), or sufficient (MET $\geq 600 /$ week) physical activity [19].

The status of smoking, drinking alcohol, and smoking water pipe were documented as either no, current, or former. These variables were recorded as current if the participant answered yes to "do you currently smoke, drink alcohol or smoke water pipe, regardless of the duration or frequency of consumption" OR recorded as 
former if the participant answered no to the last question but yes to "Did you use to smoke, drink alcohol, or smoke water pipe in the past and had quitted?"

Diabetes mellitus (DM) was defined as fasting plasma glucose levels (FBS) > $126 \mathrm{mg} / \mathrm{dL}$, previously diagnosed DM by physician, or current intake of antidiabetic agents [20]. We documented heart disease if the participant reported any history of myocardial infarction, angiography, or any other related heart diseases. The positive family history of HTN was considered if the participant reported a history of HTN in the first-degree relatives. Dyslipidemia (DLP) was defined as either serum total cholesterol $\geq 200 \mathrm{mg} / \mathrm{dL}$, HDL cholesterol $<35 \mathrm{mg} / \mathrm{dL}$, LDL cholesterol $\geq 130 \mathrm{mg} / \mathrm{dL}$, or use of lipid-lowering medication [21].

\section{Statistical analysis}

Multiple logistic regression was performed to identify the independent factors associated with prevalence, awareness, treatment, and control of HTN based on 2017 ACC/AHA guideline in the studied population. The final model was adjusted with established risk factors of HTN such as sex, age, BMI, and physical activity. The graphs were presented by GraphPad Prism 7 (GraphPad Prism Software, San Diego, CA, USA) and the statistical analysis was performed using STATA/SE version 12.0 software (STATA Corp., TX, USA). p-value $<0.05$ was considered as statistically significant.

\section{Results}

HTN indicators: 2017 ACC/AHA versus JNC8 hypertension guidelines

A total number of 30,506 individuals aged 20-65 years participated in this study. We excluded 82 subjects with missing information on SBP or DBP and included 30, 424 participants in the final analysis. The mean $( \pm \mathrm{SD})$ age was $41.71( \pm 11.89)$, and $64.26 \%$ of the participants were female.

According to JNC8 report, the overall prevalence of HTN in the studied population was $15.81 \%$, which considerably increased to $42.85 \%$ after adopting the 2017 ACC/AHA guideline (Table 1). This difference was more dominant in male $(17.79 \%$ vs $50.3 \%)$ and individuals between 45 and 54 years old (22.28 to $52.73 \%$ ). Although $3.36 \%$ of the $<25$ years old were diagnosed with HTN based on JNC8, this level increased to $24.44 \%$ by applying the new guideline.

Among HTN-identified people, $45.85 \%$ were aware. About $35.42 \%$ of self-aware individuals received antiHTN medication, which lowered the HTN to $<90 / 140$ $\mathrm{mmHg}$ in $59.63 \%$ of subjects. Nevertheless, after implementation of $2017 \mathrm{ACC} / \mathrm{AHA}$, the rate of awareness, treatment, and control dropped to $22.72 \%, 26.37$, and $28.94 \%$, respectively (Table 1 ).
The most dominated changes in prevalence and awareness of HTN were observed among 45-54 years old, but young people less than 25 were more vulnerable in terms of treatment and control.

\section{Individual characteristics associated with HTN indicators according to the 2017 ACC/AHA guideline}

Using 2017 ACC/AHA cut-off, the overall prevalence of HTN in Khuzestan province was 13,036 (42.85\%), which changed to $39.4 \%$ after sex and age adjustment. In the studied population, the mean $( \pm \mathrm{SD})$ age of hypertensive people was significantly higher than non-hypertensive people $(\mathrm{P}=0.000)$ and women were $41 \%$ less likely to manifest HTN compared to men (OR 0.59, 95\% CI 0.56-0.62). Other independent protective factors were being Bakhtiary, getting married, having higher education level, doing more physical activity, and smoking, whereas being Arab, having high WHR and BMI, drinking alcohol, and having a family history of HTN were positively associated with prevalence of HTN (Table 2).

Older people ( $\geq 35$ years old), females, not single individuals, and those with high level of BMI $\left(>25 \mathrm{~kg} / \mathrm{m}^{2}\right)$ and WHR $(\geq 0.85)$, a family history of HTN, history of DM, and CVD are more likely to be aware of HTN. Receiving HTN treatment was more prevalent in Lor people, those with history of DLP, and higher educated subjects ( $\geq 9$ years). Individuals with history of CVD had $58 \%$ higher HTN control level after taking the HTN medication comparing to those with no CVD history (Table 2).

Although Arab people are 18\% more likely to develop HTN comparing to Fars (OR 1.18, 95\% CI 1.10-1.26), they were $76 \%$ less likely to receive HTN treatment (OR $0.24,95 \%$ CI $0.19-0.30$ ) and $71 \%$ less likely to have controlled HTN after receiving the anti-HTN drug (OR $0.29,95 \%$ CI 0.19-0.46). Awareness was more prevalent in overweight, obese, and those with WHR $>0.85$. However, control of the treatment was $51 \%$ less prevalent in obese people (OR 0.49, 95\% CI 0.33-0.75).

People with higher socioeconomic status had lower prevalence of HTN; however, there was no significant association between socioeconomic status and awareness, treatment, and control of the HTN (Table 2). Moreover, HTN was less prevalent in those with sufficient activity (OR 0.85 , 95\% CI $0.80-0.91$ ) but the highly active people were less likely to be aware (OR 0.83 , 95\% CI 0.74-0.92) of HTN (Table 2).

In the nutrient assessment, we found no significant differences in the dietary habits of hypertensive and nonhypertensive group. In the sex stratification analysis, high fat intake was two-times more prevalent in hypertensive male population. In addition, a lower intake of salt and carbohydrate was observed in age group of 20 29 with HTN (data not shown). 
Table 1 Prevalence of hypertension and percentage of hypertension awareness, treatment, and control in Khuzestan province: 2017 ACC/AHA guideline vs NCJ8 report

\begin{tabular}{|c|c|c|c|c|c|c|c|c|}
\hline \multirow{2}{*}{$\begin{array}{l}\text { Determinants of } \\
\text { hypertension }\end{array}$} & \multicolumn{2}{|l|}{ Prevalence } & \multicolumn{2}{|l|}{ Awareness } & \multicolumn{2}{|l|}{ Treatment } & \multicolumn{2}{|l|}{ Control } \\
\hline & $\begin{array}{l}2017 \mathrm{ACC} / \\
\mathrm{AHA}\end{array}$ & JNC88 & $\begin{array}{l}2017 \text { ACC/ } \\
\text { AHA }\end{array}$ & JNC8 & $\begin{array}{l}2017 \mathrm{ACC} / \\
\mathrm{AHA}\end{array}$ & JNC8 & $\begin{array}{l}2017 \mathrm{ACC} / \\
\mathrm{AHA}\end{array}$ & JNC8 \\
\hline Overall & 42.85 & 15.81 & 22.72 & 45.85 & 26.37 & 35.42 & 28.94 & 59.63 \\
\hline Mean age $( \pm S D)$ & $45.72(11.71)$ & $\begin{array}{l}50.4 \\
(10.17)\end{array}$ & $53.45(8.11)$ & $\begin{array}{l}53.75 \\
(7.89)\end{array}$ & $54.36(7.51)$ & $\begin{array}{l}54.36 \\
(7.51)\end{array}$ & $51.91(9.72)$ & $\begin{array}{l}53.06 \\
(8.84)\end{array}$ \\
\hline \multicolumn{9}{|l|}{ Age group } \\
\hline$<25$ & 24.44 & 3.36 & 1.94 & 7.04 & 20.0 & 40.00 & 66.67 & 83.33 \\
\hline $25-34$ & 28.53 & 4.81 & 3.18 & 12.13 & 17.14 & 26.67 & 66.67 & 83.33 \\
\hline $35-44$ & 36.95 & 9.95 & 11.45 & 29.23 & 20.65 & 30.04 & 36.84 & 67.37 \\
\hline $45-54$ & 52.73 & 22.28 & 27.49 & 48.54 & 25.10 & 33.65 & 29.31 & 57.93 \\
\hline $55-64$ & 65.32 & 35.52 & 41.20 & 57.68 & 29.25 & 38.43 & 25.26 & 58.32 \\
\hline$=65$ & 75.45 & 45.51 & 53.17 & 68.42 & 22.39 & 28.85 & 13.33 & 40.00 \\
\hline \multicolumn{9}{|l|}{ Gender } \\
\hline Male & 50.30 & 17.79 & 14.90 & 31.06 & 24.91 & 33.78 & 26.51 & 54.62 \\
\hline Female & 38.70 & 14.70 & 28.38 & 55.81 & 26.92 & 36.03 & 29.85 & 61.49 \\
\hline \multicolumn{9}{|l|}{ Marital status } \\
\hline Single & 31.02 & 5.75 & 4.61 & 16.27 & 23.08 & 35.29 & 50.00 & 75.00 \\
\hline Married & 43.89 & 16.56 & 23.16 & 45.68 & 26.02 & 34.96 & 29.17 & 59.62 \\
\hline Divorced & 38.66 & 12.89 & 21.74 & 43.48 & 10.00 & 15.00 & 50.00 & 75.00 \\
\hline Widowed & 58.38 & 31.57 & 45.63 & 64.69 & 31.31 & 40.83 & 22.73 & 56.36 \\
\hline \multicolumn{9}{|l|}{ Socioeconomic status } \\
\hline Q1 & 42.67 & 16.01 & 22.06 & 44.47 & 26.88 & 35.54 & 27.39 & 55.22 \\
\hline Q2 & 43.99 & 16.27 & 22.92 & 46.23 & 26.46 & 35.46 & 29.78 & 60.44 \\
\hline Q3 & 41.55 & 14.90 & 22.30 & 46.63 & 27.54 & 36.72 & 27.60 & 58.40 \\
\hline Q4 & 43.39 & 16.23 & 23.85 & 46.46 & 24.79 & 34.02 & 31.46 & 65.26 \\
\hline \multicolumn{9}{|l|}{ Education } \\
\hline Illiterate & 54.40 & 26.58 & 35.00 & 56.10 & 25.54 & 32.62 & 24.83 & 52.68 \\
\hline Elementary school & 45.43 & 16.85 & 22.39 & 45.08 & 25.55 & 34.20 & 26.19 & 59.92 \\
\hline Guidance school & 40.87 & 14.41 & 20.73 & 41.93 & 24.87 & 34.89 & 35.83 & 64.17 \\
\hline High school & 38.02 & 11.65 & 16.10 & 37.15 & 29.11 & 41.18 & 33.15 & 67.39 \\
\hline Universities & 33.29 & 8.55 & 13.65 & 35.95 & 30.68 & 45.38 & 33.85 & 60.00 \\
\hline \multicolumn{9}{|l|}{ Ethnicity } \\
\hline Fars & 45.63 & 18.08 & 24.24 & 46.05 & 39.26 & 52.15 & 35.64 & 70.24 \\
\hline Arab & 44.68 & 15.46 & 21.47 & 44.64 & 13.37 & 18.58 & 16.74 & 45.58 \\
\hline Bakhtiary & 36.79 & 14.13 & 24.14 & 47.68 & 33.17 & 43.71 & 31.65 & 59.92 \\
\hline Lor & 42.84 & 17.68 & 23.28 & 46.71 & 50.52 & 61.00 & 28.98 & 59.09 \\
\hline Others & 36.73 & 8.85 & 21.69 & 50.00 & 5.56 & 10.00 & 100.00 & 100.00 \\
\hline \multicolumn{9}{|l|}{ BMI } \\
\hline Normal (18.6-25) & 32.98 & 9.60 & 13.31 & 32.25 & 28.68 & 40.65 & 37.84 & 68.92 \\
\hline Underweight ( $\leq 18.5$ ) & 22.17 & 4.75 & 6.04 & 25.64 & 36.36 & 40.00 & 62.50 & 87.50 \\
\hline Overweight (25.1-30) & 44.00 & 16.09 & 22.09 & 44.99 & 25.68 & 34.46 & 30.09 & 60.47 \\
\hline Obese $(>30)$ & 53.00 & 22.56 & 29.72 & 52.60 & 26.20 & 34.78 & 24.23 & 55.34 \\
\hline \multicolumn{9}{|l|}{ Waist-hip ratio (WHR) } \\
\hline WHR $<0.85$ & 27.63 & 6.29 & 12.12 & 38.83 & 28.47 & 39.00 & 37.96 & 71.30 \\
\hline
\end{tabular}


Table 1 Prevalence of hypertension and percentage of hypertension awareness, treatment, and control in Khuzestan province: 2017 ACC/AHA guideline vs NCJ8 report (Continued)

\begin{tabular}{|c|c|c|c|c|c|c|c|c|}
\hline \multirow{2}{*}{$\begin{array}{l}\text { Determinants of } \\
\text { hypertension }\end{array}$} & \multicolumn{2}{|l|}{ Prevalence } & \multicolumn{2}{|l|}{ Awareness } & \multicolumn{2}{|l|}{ Treatment } & \multicolumn{2}{|l|}{ Control } \\
\hline & $\begin{array}{l}2017 \text { ACC/ } \\
\text { AHA }\end{array}$ & JNC88 & $\begin{array}{l}2017 \text { ACC/ } \\
\text { AHA }\end{array}$ & JNC8 & $\begin{array}{l}2017 \text { ACC/ } \\
\text { AHA }\end{array}$ & JNC8 & $\begin{array}{l}2017 \mathrm{ACC} / \\
\text { AHA }\end{array}$ & JNC8 \\
\hline $0.85 \leq W H R<0.9$ & 38.64 & 11.70 & 17.24 & 42.39 & 25.06 & 33.66 & 36.80 & 69.60 \\
\hline $0.90 \leq W H R<0.95$ & 47.33 & 17.15 & 21.80 & 43.74 & 26.62 & 36.62 & 27.47 & 61.80 \\
\hline WHR $\geq 0.95$ & 56.42 & 26.53 & 30.81 & 49.53 & 26.27 & 34.76 & 25.33 & 53.11 \\
\hline \multicolumn{9}{|l|}{ Physical activity } \\
\hline $\begin{array}{l}\text { Insufficient (MET<600/ } \\
\text { week) }\end{array}$ & 51.81 & 21.63 & 24.71 & 45.49 & 25.48 & 33.15 & 26.70 & 55.83 \\
\hline $\begin{array}{l}\text { Sufficient (MET } \geq 600 \text { / } \\
\text { week) }\end{array}$ & 40.76 & 14.45 & 22.10 & 45.93 & 26.82 & 36.40 & 29.59 & 60.73 \\
\hline \multicolumn{9}{|l|}{ Smoking } \\
\hline No & 42.17 & 15.50 & 23.27 & 47.12 & 27.20 & 36.55 & 28.08 & 59.48 \\
\hline Current & 44.64 & 14.65 & 14.96 & 32.06 & 18.06 & 25.69 & 44.74 & 65.79 \\
\hline Former & 57.25 & 27.03 & 26.75 & 44.87 & 20.13 & 25.42 & 32.43 & 56.76 \\
\hline \multicolumn{9}{|l|}{ Water pipe (hookah) } \\
\hline No & 42.77 & 15.94 & 23.29 & 46.50 & 26.16 & 35.15 & 29.06 & 59.59 \\
\hline Current & 42.77 & 11.99 & 11.13 & 28.68 & 33.33 & 46.15 & 20.00 & 65.00 \\
\hline Former & 47.69 & 16.70 & 18.89 & 42.11 & 31.71 & 40.62 & 33.33 & 55.56 \\
\hline \multicolumn{9}{|l|}{ Family history BP } \\
\hline No & 40.55 & 13.58 & 17.17 & 37.77 & 25.86 & 35.10 & 28.39 & 60.05 \\
\hline Yes & 46.37 & 19.22 & 30.24 & 54.75 & 26.75 & 35.66 & 29.37 & 59.31 \\
\hline \multicolumn{9}{|l|}{ History of DLP } \\
\hline No & 37.94 & 12.40 & 20.67 & 44.91 & 22.24 & 31.32 & 27.99 & 61.95 \\
\hline Yes & 47.71 & 19.18 & 24.34 & 46.45 & 29.13 & 37.96 & 29.45 & 58.40 \\
\hline \multicolumn{9}{|l|}{ History of DM } \\
\hline No & 39.74 & 13.16 & 17.85 & 40.15 & 26.61 & 35.72 & 31.38 & 61.21 \\
\hline Yes & 60.67 & 30.98 & 41.02 & 59.76 & 25.98 & 34.93 & 24.78 & 56.93 \\
\hline \multicolumn{9}{|l|}{ History of CVD } \\
\hline No & 41.57 & 14.43 & 19.30 & 41.62 & 25.64 & 34.24 & 27.14 & 57.42 \\
\hline Yes & 65.03 & 39.89 & 61.63 & 73.19 & 28.83 & 39.58 & 34.00 & 65.20 \\
\hline
\end{tabular}

The economic status was defined based on the wealth index, which was calculated by multiple correspondence analysis (MCA) with household's ownership of selected assets. Physical activity was estimated by metabolic equivalent of task (MET) category, which was calculated based on the international physical activity questionnaire (IPAQ) guideline. Dyslipidaemia was defined as either serum total cholesterol $\geq 200 \mathrm{mg} / \mathrm{dL}$, high-density lipoprotein (HDL) cholesterol $<35 \mathrm{mg} / \mathrm{dL}$, or low-density lipoprotein (LDL) cholesterol $\geq 130 \mathrm{mg} / \mathrm{dL}$ or use of lipid-lowering medication. Diabetes Mellitus was defined as fasting plasma glucose levels (FBS) > $126 \mathrm{mg} / \mathrm{dL}$, previously diagnosed DM, or current intake of antidiabetic agents. Cardiovascular diseases was defined if the participant reported any history of myocardial infarction, angiography, or any other related heart diseases.

JNC8 eighth report of the Joint National Committee, ACC/AHA 2017 American College of Cardiology/American Heart Association, BMI body mass index, MET metabolic equivalent of task, DLP dyslipidemia, DM diabetes mellitus, CVD cardiovascular diseases, $Q$ quartile

\section{Discussion}

After implementation of the 2017 ACC/AHA guideline, the prevalence of HTN in the Khuzestan province increased from 15.81 to $42.85 \%$ and the level of awareness (from 45.85 to $22.72 \%$ ), treatment (from 35.42 to $26.37 \%$ ), and control (from 59.63 to $28.94 \%$ ) dramatically dropped. Since Khuzestan had the lowest level of healthcare development, and highest inequality of health services utilization in the country, a great need to expand the public health infrastructure for progressing towards the goals of UHC of HTN in this province is required.

In order to reduce the major adverse of CVD events, ACC/AHA has recommended a lower threshold of SBP and DBS (130/80 mm Hg) for diagnosis of HTN compared to what had been suggested earlier $(140 / 90 \mathrm{~mm}$ $\mathrm{Hg}$ ); however, there are debates about the proposed HTN cut-off and CVD benefit. Some studies reported reducing the $\mathrm{SBP}$ to $120 \mathrm{~mm} \mathrm{Hg}$ level significantly 
Table 2 Individual characteristics associated with prevalence, awareness, treatment, and control of hypertension according to the 2017 ACC/AHA guideline

\begin{tabular}{|c|c|c|c|c|}
\hline $\begin{array}{l}\text { Determinants of } \\
\text { hypertension }\end{array}$ & $\begin{array}{l}\text { Prevalence } \\
\text { OR }(95 \% \mathrm{CI})^{\mathrm{a}}\end{array}$ & $\begin{array}{l}\text { Awareness } \\
\text { OR }(95 \% \mathrm{Cl})^{\mathrm{a}}\end{array}$ & $\begin{array}{l}\text { Treatment } \\
\text { OR }(95 \% \mathrm{CI})^{\mathrm{a}}\end{array}$ & $\begin{array}{l}\text { Control } \\
\text { OR }(95 \% \mathrm{Cl})^{\mathrm{a}}\end{array}$ \\
\hline \multicolumn{5}{|l|}{ Age group } \\
\hline$<25$ & 1 & 1 & 1 & 1 \\
\hline $25-34$ & $1.09(0.97-1.22)$ & $1.44(0.74-2.83)$ & $0.83(0.16-4.41)$ & $1.45(0.21-10.06)$ \\
\hline $35-44$ & $1.45(1.29-1.62)$ & $4.96(2.63-9.48)$ & $1.07(0.22-5.16)$ & $0.41) 0.07-2.45)$ \\
\hline $45-54$ & $2.64(2.36-2.96)$ & $14.3(15.2-53.9)$ & $1.4(0.29-6.50)$ & $0.31(0.05-1.83)$ \\
\hline $55-64$ & $4.47(3.98-5.03)$ & $28.45(15.2-53.9)$ & $1.74(0.37-8.23)$ & $0.24) 0.04-1.41)$ \\
\hline$=65$ & $7.29(5.02-10.58)$ & $51.2(24.8-105.9)$ & $1.22(0.23-6.14)$ & $0.11(0.01-1.05)$ \\
\hline \multicolumn{5}{|l|}{ Gender } \\
\hline Male & 1 & 1 & 1 & 1 \\
\hline Female & $0.59(0.56-0.62)$ & $2.22(2.01-2.46)$ & $1.16(0.96-1.42)$ & $1.22(0.86-1.74)$ \\
\hline \multicolumn{5}{|l|}{ Marital status } \\
\hline Single & 1 & 1 & 1 & 1 \\
\hline Married & $0.90(0.83-0.98)$ & $2.02(1.49-2.76)$ & $1.14(0.59-2.21)$ & $0.73(0.27-1.95)$ \\
\hline Divorced & $0.94(0.74-1.2)$ & $1.85(1.09-3.15)$ & $0.34(0.09-1.32)$ & $1.28(0.14-12.12)$ \\
\hline Widowed & $1.11(0.95-1.29)$ & $2.24(1.59-3.19)$ & $1.33(0.66-2.69)$ & $0.58(0.20-1.70)$ \\
\hline \multicolumn{5}{|l|}{ Socioeconomic status } \\
\hline Q1 & 1 & 1 & 1 & 1 \\
\hline Q2 & $1.00(0.93-1.07)$ & $1.06(0.93-1.20)$ & $0.97(0.77-1.22)$ & $1.22(0.80-1.85)$ \\
\hline Q3 & $0.88(0.83-0.95)$ & $1.07(0.95-1.23)$ & $1.03(0.81-1.30)$ & $1.16(0.76-1.75)$ \\
\hline Q4 & $0.83(0.77-0.89)$ & $1.11(0.98-1.27)$ & $0.89(0.70-1.13)$ & $1.37(0.89-2.11)$ \\
\hline \multicolumn{5}{|l|}{ Education (year study) } \\
\hline Illiterate $(<1)$ & 1 & 1 & 1 & 1 \\
\hline Elementary school (1-5) & $0.85(0.79-0.92)$ & $0.84(0.74-0.95)$ & $1.09(0.88-1.35)$ & $1.07(0.72-1.60)$ \\
\hline Guidance school (6-8) & $0.74(0.68-0.81)$ & $1.04(0.89-1.21)$ & $1.09(0.83-1.44)$ & $1.59(0.99-2.58)$ \\
\hline High school (9-12) & $0.73(0.68-0.79)$ & $0.87(0.76-0.99)$ & $1.36(1.06-1.74)$ & $1.34(0.87-2.07)$ \\
\hline Universities (>12) & $0.66(0.60-0.73)$ & $1.00(0.82-1.22)$ & $1.55(1.06-2.25)$ & $1.44(0.77-2.70)$ \\
\hline \multicolumn{5}{|l|}{ Ethnicity } \\
\hline Fars & 1 & 1 & 1 & 1 \\
\hline Arab & $1.18(1.10-1.26)$ & $1.10(0.98-1.24)$ & $0.24(0.19-0.30)$ & $0.29(0.19-0.46)$ \\
\hline Bakhtiary & $0.78(0.72-0.84)$ & $1.07(0.93-1.23)$ & $0.75(0.59-0.96)$ & $0.71) 0.48-1.04)$ \\
\hline Lor & $0.99(0.90-1.09)$ & $0.96(0.81-1.15)$ & $1.53(1.15-2.04)$ & $0.67(0.44-1.02)$ \\
\hline Others & $0.74(0.56-0.99)$ & $0.94(0.53-1.69)$ & $0.09(0.01-0.66)$ & Not enough \\
\hline \multicolumn{5}{|l|}{ BMI } \\
\hline Normal (18.6-25) & 1 & 1 & 1 & 1 \\
\hline Underweight ( $\leq 18.5)$ & $0.65(0.55-0.78)$ & $0.59(0.31-1.14)$ & $1.35(0.39-4.73)$ & $1.64(0.34-7.90)$ \\
\hline Overweight (25.1-30) & $1.46(1.37-1.55)$ & $1.57(1.37-1.80)$ & $0.86(0.66-1.11)$ & $0.68) 0.45-1.04)$ \\
\hline Obese $(>30)$ & $2.15(2.01-2.29)$ & $2.09(1.82-2.39)$ & $0.88(0.68-1.14)$ & $0.49(0.33-0.75)$ \\
\hline \multicolumn{5}{|l|}{ Waist-hip ratio (WHR) } \\
\hline WHR $<0.85$ & 1 & 1 & 1 & 1 \\
\hline $0.85 \leq W H R<0.9$ & $1.23(1.14-1.33)$ & $1.24(1.04-1.48)$ & $0.84(0.59-1.19)$ & 1.23 )0.70-2.17) \\
\hline $0.90 \leq W H R<0.95$ & $1.43(1.33-1.54)$ & $1.44(1.21-1.70)$ & $0.91(0.66-1.24)$ & $0.83(0.49-1.39)$ \\
\hline WHR $\geq 0.95$ & $1.58(1.46-1.70)$ & $1.75(1.49-2.06)$ & $0.88(0.65-1.18)$ & $0.86(0.53-1.42)$ \\
\hline
\end{tabular}


Table 2 Individual characteristics associated with prevalence, awareness, treatment, and control of hypertension according to the 2017 ACC/AHA guideline (Continued)

\begin{tabular}{|c|c|c|c|c|}
\hline $\begin{array}{l}\text { Determinants of } \\
\text { hypertension }\end{array}$ & $\begin{array}{l}\text { Prevalence } \\
\text { OR }(95 \% \mathrm{Cl})^{\mathrm{a}}\end{array}$ & $\begin{array}{l}\text { Awareness } \\
\text { OR }(95 \% \mathrm{CI})^{\mathrm{a}}\end{array}$ & $\begin{array}{l}\text { Treatment } \\
\text { OR }(95 \% \mathrm{CI})^{\mathrm{a}}\end{array}$ & $\begin{array}{l}\text { Control } \\
\text { OR }(95 \% \mathrm{Cl})^{\mathrm{a}}\end{array}$ \\
\hline \multicolumn{5}{|l|}{ Physical activity } \\
\hline Insufficient (MET<600/week) & 1 & 1 & 1 & 1 \\
\hline Sufficient (MET $\geq$ 600/week) & $0.85(0.80-0.91)$ & $0.83(0.74-0.92)$ & $1.12(0.91-1.37)$ & $0.98(0.67-1.43)$ \\
\hline \multicolumn{5}{|l|}{ Smoking } \\
\hline No & 1 & 1 & 1 & 1 \\
\hline Current & $0.80(0.72-0.88)$ & $1.04(0.85-1.28)$ & $0.58(0.37-0.89)$ & $2.51(1.23-5.10)$ \\
\hline Former & $0.96(0.84-1.11)$ & $1.21(0.98-1.51)$ & $0.66(0.43-01.00)$ & $1.67) 0.78-3.54)$ \\
\hline \multicolumn{5}{|l|}{ Water pipe (hookah) } \\
\hline No & 1 & 1 & 1 & 1 \\
\hline Current & $1.15(1.01-1.31)$ & $0.92(0.66-1.26)$ & $1.52(0.85-2.70)$ & $0.54(0.17-1.68)$ \\
\hline Former & $1.24(1.02-1.51)$ & $1.25(0.85-1.86)$ & $1.19(0.60-2.36)$ & $1.12(0.38-3.31)$ \\
\hline \multicolumn{5}{|l|}{ Family history BP } \\
\hline No & 1 & 1 & 1 & 1 \\
\hline Yes & $1.35(1.28-1.42)$ & $2.37(2.16-2.61)$ & $1.09(0.92-1.29)$ & $1.07(0.79-1.45)$ \\
\hline \multicolumn{5}{|l|}{ History of DLP } \\
\hline No & 1 & 1 & 1 & \\
\hline Yes & $1.10(1.04-1.15)$ & $0.90(0.82-0.99)$ & $1.41(1.19-1.68)$ & $1.15(0.84-1.58)$ \\
\hline \multicolumn{5}{|l|}{ History of DM } \\
\hline No & 1 & 1 & 1 & 1 \\
\hline Yes & $1.50(1.40-1.61)$ & $2.04(1.85-2.25)$ & $0.94(0.79-1.11)$ & $0.81(0.59-1.10)$ \\
\hline \multicolumn{5}{|l|}{ History of CVD } \\
\hline No & 1 & 1 & 1 & 1 \\
\hline Yes & $1.45(1.30-1.63)$ & $4.23(3.66-4.88)$ & $1.16(0.95-1.41)$ & $1.57(1.13-2.20)$ \\
\hline
\end{tabular}

The economic status was defined based on the wealth index, which was calculated by multiple correspondence analysis (MCA) with household's ownership of selected assets. Physical activity was estimated by metabolic equivalent of task (MET) category, which was calculated based on the international physical activity questionnaire (IPAQ) guideline. Dyslipidemia was defined as either serum total cholesterol $\geq 200 \mathrm{mg} / \mathrm{dL}$, high-density lipoprotein (HDL) cholesterol $<35 \mathrm{mg} / \mathrm{dL}$, or low-density lipoprotein (LDL) cholesterol $\geq 130 \mathrm{mg} / \mathrm{dL}$ or use of lipid-lowering medication. Diabetes Mellitus was defined as fasting plasma glucose levels (FBS) > $126 \mathrm{mg} / \mathrm{dL}$, previously diagnosed DM, or current intake of antidiabetic agents. Cardiovascular diseases was defined if the participant reported any history of myocardial infarction, angiography, or any other related heart diseases. Bold values indicate statistical significance

JNC8 eighth report of the Joint National Committee, ACC/AHA 2017 American College of Cardiology/American Heart Association, BMI body mass index, MET metabolic equivalent of task, DLP dyslipidemia, DM diabetes mellitus, CVD cardiovascular diseases, $O R$ odds ratio, $C l$ confidence interval, $Q$ quartile

${ }^{a}$ Odds ratios were adjusted for age, gender, BMI, and physical activity

decreased the risk of CVD [22], and a substantial reduction in risk was observed for levels SBP/DBP below 130$139 \mathrm{~mm} \mathrm{Hg}[23,24]$. However, a recent systematic review and meta-analysis study found no reduction in risk of CVD-related death by reducing the cut-off from additional blood pressure lowering if the SBP at baseline was $<140 \mathrm{~mm} \mathrm{Hg}$ [25] and the authors further declared implementation of this guideline caused a significant increase in the proportion of adult diagnosed with HTN, with no noticeable effect on the reducing CVD morbidly and mortality [26]. Here, we found the number of hypertensive patients in Khuzestan province increased from $4809(15.81 \%)$ to $13,036(42.85 \%)$. A lower changes have been documented in other countries like China $(>18$ years) [27], USA (>20 years) [28], and Sweden (25-74 years) [26] in comparison with the previous report from Iran ( $>25$ years) [6], which indicates the number of people with SBP $130-140$ or DBP $80-90$ was higher in Iran and our country would gain greater benefit of reduction in CVD mortality in the future if the 2017 ACC/ AHA guideline is implemented.

The increased prevalence of HTN was observed in all age group of Khuzestan population: lowest in under 25 years of age (from 3.36 to $24.44 \%$ ) and highest in 45-54 years old individuals (from 22.28 to $52.73 \%$ ). Although Khuzestan has critical health issues, the overall prevalence of HTN in this province is lower than the estimated HTN prevalence in Iran [6] (Fig. 1a) and the effect of new guideline on older population of Khuzestan was more dominated than overall population of the 
country. Moreover, a noticeable shift of HTN prevalence has been observed among male population. Although almost equal number of male and female were diagnosed with HTN previously (17.79\% vs $14.70 \%$ ), we observed a more significant increase in HTN among male after applying the 2017 guideline (50.30\% vs $38.70 \%$ ).

According to the JNC8 report, we found that $45.85 \%$ of the hypertensive participants in Khuzestan province were aware of HTN, which is lower than the overall awareness estimates in the country [6] (Fig. 1a). Khuzestan has the lowest level of healthcare development within country [13], which required investment of more efforts to improve the health education in the community. After adopting the 2017 ACC/AHA, the awareness rate dropped to $22.72 \%$, which was more noticeable in the $45-54$ age group. Since $52.73 \%$ of this age group are now classified under the HTN category, a substantial call for action to raise public awareness is warranted.

Moreover, the HTN treatment strategy has been revised in the 2017 ACC/AHA guideline and those with SBP $130-139$ or DBP of $80-89$ were also recommended to received anti-HTN treatment if they are +65 years older, or the clinical CVD or 10-year atherosclerotic cardiovascular disease risk is $10 \%$ or greater [7]. Following this guideline, many high-risk adults might be protected against the development of HTN-related chronic diseases. However, the number of people who need antiHTN treatment has been expected to increase from 8.1 million to 15.6 million in the USA and from 74.5 million to 129.8 million in China [8], which may impose a considerable impact on the health system in these countries. In this study, 4738 (15.53\%) of total sample were eligible to receive HTN therapy based on JNC8. After ACC/ AHA, additional 1724 subjects with SBP $130-139$ or DBP of 80-89 and history of CVD or DM become candidate for pharmacological interventions, which increase the treatment demand to $21.18 \%$. However, our study was limited to people aged 65 and younger and estimating the real impact of this guideline on treatment eligibility in our population was not feasible. Another recent study conducted in Iran estimated that the number of adults who met the criteria for treatment with antihypertensive medication would increase from 13.4 million to 17.2 million and the annual cost of
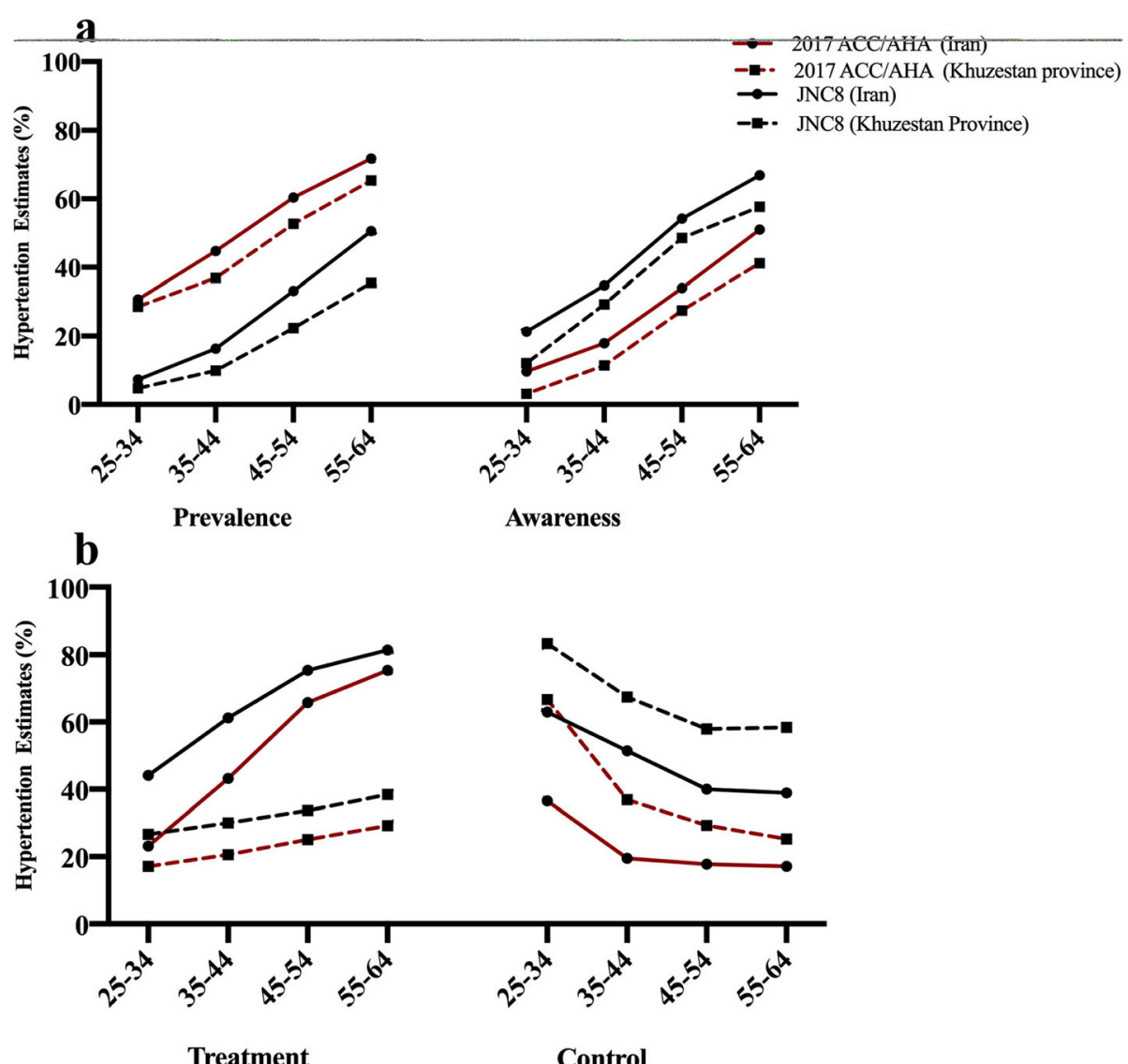

Fig. 1 The impact of 2017ACC/AHA and JNC8 guidelines on the prevalence, awareness (a), treatment, and control (b) of hypertension in different age groups in Khuzestan province, comparing to the national average rates of prevalence, awareness, treatment, and control of hypertension 
pharmacologic therapy would change from $\$ 510$ million to $\$ 653$ million [6]. Although the increased prevalence of HTN was more noticeable in Iran, the treatment burden in this country was lower compared to China and the USA, which might be due to smaller population of $65+$ years old in Iran. Therefore, the impact of treatment costs on the health system under the 2017 ACC/AHA guideline slightly increased.

However, in Khuzestan province, the effect of new guideline would be more noticeable. For example, based on JNC8 report, an average of $81.4 \%$ of self-aware individuals between 55 and 64 years old received HTN treatment at the national level [6] but this level among the same age group in Khuzestan was $38.43 \%$ (Fig. 1b), which indicates a serious lack of HTN treatment among hypertensive people in this province. The inequality of health services utilization in this province is the main cause of lower treatment rate in this province. This inequality was also observed among different ethnicity groups within the province. Although Arab people are $18 \%$ more likely to develop HTN comparing to Fars (OR $1.18,95 \%$ CI $1.10-1.26)$, they were $76 \%$ less likely to receive HTN treatment and $71 \%$ less likely to have controlled HTN after receiving the anti-HTN drug. HTN treatment also was $25 \%$ less prevalent in Bakhtiary people. Although, Khuzestan is most industrialized province in the country, it is the most deprived province in the country in term of healthcare. Therefore, implementation of the 2017 ACC/AHA guideline may considerably delay the progression towards UHC of HTN in this province.

Among treated individuals, 59.63\% had blood pressure $<130 / 80 \mathrm{mmHg}$. Under ACC/AHA guideline, the blood pressure $<130 / 80 \mathrm{~mm} \mathrm{Hg}$ was considered as the target cut-off; therefore, the control rate dropped to $28.94 \%$, which highlight a great need to expand the public health infrastructure for further managing the substantial increase in the public health burden of HTN. Although the treatment rate in Khuzestan was much lower than mean percentage of the country, the controlled level was higher in this province (Fig. 1b).

Considering the 2017 ACC/AHA guideline, 6574 participants younger than 65 years old have been additionally diagnosed with HTN, who might benefit from earlier interventions. Apart from high-risk individuals, this group of people are not eligible for pharmacological interventions; therefore, modification of life style and nutrient diet is critical to reduce the risk of HTN-related disorders in the future. For example, $22.56 \%$ of obese precipitants were diagnosed with HTN previously, and this value jumped to $53 \%$. Although HTN was $15 \%$ less prevalent in those with sufficient activity, they were $17 \%$ less likely to be aware of HTN. In this study, the mean of sodium intake was estimated to be $8.74 \mathrm{~g} /$ day, which exceeds the current WHO recommendations (2 g/day (d) of sodium, equivalent to $5 \mathrm{~g} / \mathrm{d}$ of salt) [29]. Based on 2017 ACC/AHA, we estimated about $79.38 \%$ of hypertensive people consume salt over the threshold, $75 \% .82$ need to lose extra weight, and $22.48 \%$ are required to do more physical activity.

Our study has certain limitations. This is a crosssectional based study, and a causal relationship cannot be inferred. Moreover, based on the HTN 2017 ACC/ AHA, those with SBP $130-139$ or DBP of $80-89$ were also recommended to receive anti-hypertension treatment if they are +65 years older. However, our study was limited to people aged 65 and younger, and further study covering all range group is required to estimate the real impact of treatment after implementation of new guideline.

\section{Conclusion}

In the ACC/AHA guideline, a higher number of individuals with the pre-hypertension condition had been shifted into the hypertension category, and the level of awareness, treatment, and control was dramatically fallen, which highlight a great need to expand the public health infrastructure for further managing the substantial increase in the public health burden of hypertension.

\begin{abstract}
Abbreviations
HTN: Hypertension; CVD: Cardiovascular diseases; JNC8: Eighth report of the joint national committee; SBP: Systolic blood pressure; DBP: Diastolic blood pressure; ACC: American College of Cardiology; AHA: American Heart Association; KCHS: Khuzestan Comprehensive Health Study; FBS: Fasting plasma glucose levels; BMI: Body mass index; WHR: Waist-to-hip ratio; MCA: Multiple correspondence analysis; MET: Metabolic equivalent of task; IPAQ: International physical activity questionnaire; HDL: High-density lipoproteins cholesterol; FFQ: Food frequency questionnaire; SD: Standard deviation
\end{abstract}

\section{Acknowledgements}

Not applicable

\section{Authors' contributions}

FS: concept, design, data analysis, interpretation, writing the article, critical reviews, final approval. BCh: data collection, critical reviews, final approval. ZM: data collection, critical reviews, final approval. SS: interpretation, critical reviews, final approval. SM: data analysis, critical reviews, final approval. ZR: data collection, critical reviews, final approval. LD: data collection, critical reviews, final approval. YP: data collection, critical reviews, final approval. FA: data collection, critical reviews, final approval. MN: data collection, critical reviews, final approval. SAM: data collection, critical reviews, final approval. AKSh: concept, design, interpretation, critical reviews, final approval. HP: concept, design, interpretation, critical reviews, final approval.

\section{Funding}

The project was funded by the National Institute for Medical Research Development (NIMAD, Grant number: 940406).

\section{Availability of data and materials}

The datasets from the current study are included within the article.

\section{Declarations}

Ethics approval and consent to participate Not applicable 


\section{Consent for publication}

Not applicable

\section{Competing interests}

The authors declare that the research was conducted in the absence of any commercial or financial relationships that could be construed as a potential conflict of interest.

\begin{abstract}
Author details
${ }^{1}$ Department of Global Public Health, Karolinska Institute, Stockholm, Sweden. ${ }^{2}$ Alimentary Tract Research Center, Imam Khomeini Hospital Clinical Research Development Unit, Department of Biostatistics and Epidemiology, School of Public Health, Ahvaz Jundishapur University of Medical Sciences, Ahvaz, Iran. ${ }^{3}$ Liver and Pancreatobiliary Diseases Research Center, Digestive Diseases Research Institute, Tehran University of Medical Sciences, Tehran, Iran. ${ }^{4}$ Digestive Disease Research Center, Digestive Disease Research Institute, Tehran University of Medical Sciences, Tehran, Iran. ${ }^{5}$ Hearing Research Center, Department of Biostatistics and Epidemiology, School of Public Health, Ahvaz Jundishapur University of Medical Sciences, Ahvaz, Iran. ${ }^{6}$ Behbahan Faculty of Medical Sciences, Behbahan, Iran. ${ }^{7}$ School of medicine, Dezful University of Medical Sciences, Dezful, Iran. ${ }^{8}$ Shoshtar Faculty of Medical Sciences, Shoshtar, Iran. ${ }^{9}$ Ahvaz Jundishapur University of Medical Sciences, Ahvaz, Iran. ${ }^{10}$ Abadan Faculty of Medical Sciences, Abadan, Iran. ${ }^{11}$ Alimentary Tract Research Center, Imam khomeini Hospital Clinical Research Development Unit, School of Medicine, Ahvaz Jundishapur University of Medical Sciences, Ahvaz, Iran.
\end{abstract}

Received: 7 September 2020 Accepted: 12 May 2021

Published online: 25 May 2021

\section{References}

1. Lawes CM, Vander Hoorn S, Rodgers A. Global burden of blood-pressurerelated disease, 2001. Lancet. 2008;371(9623):1513-8. https://doi.org/10.101 6/s0140-6736(08)60655-8.

2. Kearney PM, Whelton M, Reynolds K, Muntner P, Whelton PK, He J. Global burden of hypertension: analysis of worldwide data. Lancet. 2005;365(9455): 217-23. https://doi.org/10.1016/s0140-6736(05)17741-1.

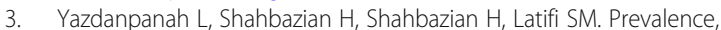
awareness and risk factors of hypertension in southwest of Iran. J Renal Inj Prev. 2015;4(2):51-6. https://doi.org/10.12861/jrip.2015.11.

4. Khodayari-Zarnaq R, Kabiri N, Alizadeh G. Health in first to sixth eonomic, social, and cultural development plans of Iran: a document analysis. J Res Health. 2020;10(1):1-10.

5. Hernandez-Vila E. A review of the JNC 8 Blood Pressure Guideline. Tex Heart Inst J. 2015;42:226-8. https://doi.org/10.14503/thij-15-5067.

6. Mahdavi M, Parsaeian M, Mohajer B, Modirian M, Ahmadi N, Yoosefi M, et al. Insight into blood pressure targets for universal coverage of hypertension services in Iran: the 2017 ACC/AHA versus JNC 8 hypertension guidelines. BMC Public Health. 2020;20(1):347. https://doi.org/10.1186/s12889-020-84 50-1.

7. Carey RM, Whelton PK. Prevention, detection, evaluation, and management of high blood pressure in adults: synopsis of the 2017 American College of Cardiology/American Heart Association Hypertension Guideline. Ann Intern Med. 2018;168(5):351-8. https://doi.org/10.7326/m17-3203.

8. Khera R, Lu Y, Lu J, Saxena A, Nasir K, Jiang L, et al. Impact of 2017 ACC/ AHA guidelines on prevalence of hypertension and eligibility for antihypertensive treatment in United States and China: nationally representative cross sectional study. BMJ. 2018;362:k2357. https://doi.org/1 $0.1136 / \mathrm{bmj} . k 2357$

9. Abariga SA, Khachan H, Al Kibria GM. Prevalence and determinants of hypertension in India based on the 2017 ACC/AHA Guideline: evidence from the India National Family Health Survey. Am J Hypertens. 2020;33:25260. https://doi.org/10.1093/ajh/hpz181.

10. Kunes J, Zicha J. The interaction of genetic and environmental factors in the etiology of hypertension. Physiol Res. 2009;58(Suppl 2):S33-41.

11. Lelong H, Blacher J, Baudry J, Adriouch S, Galan P, Fezeu L, et al. Individual and combined effects of dietary factors on risk of incident hypertension: prospective analysis from the NutriNet-Santé cohort. Hypertension. 2017 70(4):712-20. https://doi.org/10.1161/hypertensionaha.117.09622.
12. Britannica. Britannica. Khūzestān, geographical region, Iran. Available from: geographical region, Iran. 2007; Available from: https://www.britannica.com/ place/Khuzestan.

13. Ahangari, A. and A. Dehghani Ahmadabad, Spatial distribution of health services in Iranian provinces at the end of the fifth development plan; 2015 (Based on Health Structural Indicators). Jundishapur J Health Sci, 2018. 10(3).

14. Cheraghian B, Sharafkhah M, Mohammadi Z, Hariri S, Rahimi Z, Danehchin L, et al. The Khuzestan Comprehensive Health Study (KCHS): methodology and profile of participants. Arch Iran Med. 2020;23(10):653-7. https://doi. org/10.34172/aim.2020.82.

15. Agriculture., U.S.D.O.; Available from: https://fdc.nal.usda.gov/.

16. Arani AM, Kakia ML, Karimi MV. Assessment in education in Iran. Assessment. 2012

17. Shea Oscar Rutstein KJ. The DHS wealth index: ORC macro, MEASURE DHS; 2004

18. Executive summary of the clinical guidelines on the identification, evaluation, and treatment of overweight and obesity in adults. Arch Intern Med, 1998. 158(17): p. 1855-67.

19. Jetté M, Sidney K, Blümchen G. Metabolic equivalents (METS) in exercise testing, exercise prescription, and evaluation of functional capacity. Clin Cardiol. 1990;13(8):555-65. https://doi.org/10.1002/clc.4960130809.

20. Classification and Diagnosis of Diabetes: Standards of Medical Care in Diabetes-2018. Diab Care, 2018. 41(Suppl 1): p. S13-s27.

21. Grundy SM, Stone NJ, Bailey AL, Beam C, Birtcher KK, Blumenthal RS, et al. 2018 AHA/ACC/AACVPR/AAPA/ABC/ACPM/ADA/AGS/APhA/ASPC /NLA/ PCNA Guideline on the Management of Blood Cholesterol: Executive Summary: a report of the American College of Cardiology/American Heart Association Task Force on Clinical Practice Guidelines. J Am Coll Cardiol. 2019;73(24):3168-209. https://doi.org/10.1016/j.jacc.2018.11.002.

22. Bundy JD, Li C, Stuchlik P, Bu X, Kelly TN, Mills KT, et al. Systolic blood pressure reduction and risk of cardiovascular disease and mortality: a systematic review and network meta-analysis. JAMA Cardiol. 2017;2(7):77581. https://doi.org/10.1001/jamacardio.2017.1421.

23. Shen $L, M a H$, Xiang MX, Wang JA. Meta-analysis of cohort studies of baseline prehypertension and risk of coronary heart disease. Am J Cardiol. 2013;112(2):266-71. https://doi.org/10.1016/j.amjcard.2013.03.023.

24. Huang Y, Wang S, Cai X, Mai W, Hu Y, Tang H, et al. Prehypertension and incidence of cardiovascular disease: a meta-analysis. BMC Med. 2013;11(1): 177. https://doi.org/10.1186/1741-7015-11-177.

25. Brunström M, Carlberg B. Association of blood pressure lowering with mortality and cardiovascular disease across blood pressure levels: a systematic review and meta-analysis. JAMA Intern Med. 2018;178(1):28-36. https://doi.org/10.1001/jamainternmed.2017.6015.

26. Brunström M, Carlberg B, Lindholm LH. Perspective from Sweden on the Global Impact of the 2017 American College of Cardiology/American Heart Association Hypertension Guidelines: A "Sprint" Beyond Evidence in the United States. Circulation. 2018;137(9):886-8. https://doi.org/10.1161/circula tionaha.118.033632.

27. Li D, Zeng $X$, Huang $Y$, Lei H, Li G, Zhang N, et al. Increased risk of hypertension in young adults in Southwest China: impact of the 2017 ACC/ AHA High Blood Pressure Guideline. Curr Hypertens Rep. 2019;21(3):21. https://doi.org/10.1007/s11906-019-0926-y.

28. Muntner P, Carey RM, Gidding S, Jones DW, Taler SJ, Wright JT Jr, et al. Potential US population impact of the 2017 ACC/AHA High Blood Pressure Guideline. Circulation. 2018;137(2):109-18. https://doi.org/10.1161/circula tionaha.117.032582.

29. Härtl G. WHO issues new guidance on dietary salt and potassium. Cent Eur J Public Health. 2013;21:16

\section{Publisher's Note}

Springer Nature remains neutral with regard to jurisdictional claims in published maps and institutional affiliations. 